\title{
Projection-type X-ray microscope based on a spherical compound refractive $\mathrm{X}$-ray lens
}

\author{
Yu.I. Dudchik ${ }^{\text {a* }}$, C.K. Gary ${ }^{\text {b }}$, H. Park ${ }^{\text {b }}$, R.H. Pantell ${ }^{\mathrm{c}}$, M.A. Piestrup ${ }^{\mathrm{b}}$ \\ ${ }^{a}$ Institute of Applied Physics Problems of Belarus State University, \\ Kurchatova 7, 220064 Minsk, Belarus \\ ${ }^{\mathrm{b}}$ Adelphi Technology, Inc., 981-B Industrial Rd, San Carlos, 94070, California \\ ${ }^{c}$ Department of Electrical Engineering, Stanford University, Stanford, 94305, California
}

\begin{abstract}
New projection- type X-ray microscope with a compound refractive lens as the optical element is presented. The microscope consists of an X-ray source that is $1-2 \mathrm{~mm}$ in diameter, compound X-ray lens and X-ray camera that are placed in-line to satisfy the lens formula. The lens forms an image of the X-ray source at camera sensitive plate. An object is placed between the X-ray source and the lens as close as possible to the source, and the camera shows a shadow image of the object. Spatial resolution of the microscope depends on the lens focal length, lens aperture and the distance from the source to the object. One to two micron resolution may be achieved by placing the object at a distance of 1-5 $\mathrm{mm}$ from the source. The X-ray source may be designed with the target deposited on a $200-\mu \mathrm{m}$ thick Be window, which permits the object to be placed very close to the emitting surface. The tube focal spot is equal to $1-2 \mathrm{~mm}$. Results of imaging experiments with an ordinary copper anode X-ray tube and a $10-\mathrm{cm}$ focal length spherical compound refractive $\mathrm{X}$-ray lens are discussed.
\end{abstract}

Keywords: X-ray imaging, compound refractive lenses

\section{INTRODUCTION}

$\mathrm{X}$-ray imaging and microscopy are well-known tools to receive information on internal structure of objects. As a rule characteristics X-rays with photon energy in the range $5-18 \mathrm{keV}$ are used to see heterogeneity in materials, products of microelectronics and biological samples. In spite of the fact that the method is well-known, its resolution power up to recent time was limited to a size of some micrometers. It has been connected basically with the absence of imaging optical devices for the given range of the spectrum. Zone plates and elements of refractive optics [1-4] changed the situation drastically: the resolution power of imaging was increased up to a submicron level . Most of experiments with refractive lenses were done with synchrotron sources which are the complex and expensive device [5-7].

The method of $\mathrm{x}$-ray microscopy is realized as well with the use of laboratory microfocus $\mathrm{x}$-ray tubes and sources [8]. In this case object for research is placed between a source of radiation and a film or CCD-camera, and the resolution of the image thus is defined basically by the size of a source. The disadvantage of the method consists that spatial location of a source of radiation, as a rule, varies eventually, therefore object imaging at one micron level seems problematic enough. This disadvantage may be overcome by using imaging optics such as zone plates and refractive lenses. For example, recently we have demonstrated that a simple X-ray microscope consisting of an ordinary X-ray tube and imaging optics in the form of compound refractive X-ray lens demonstrates spatial resolution at the 3-5-micron level with a 1-mm field of view [9]. The lens used for the microscope consists of 104 individual epoxy spherical microlenses formed inside a glass capillary. The curvature radius of each microlens is equal to 100 microns, providing $13.5 \mathrm{~cm}$ lens focal lengths for $8 \mathrm{keV} \mathrm{X}$-rays. An image is formed by X-rays scattered by the object and collected by the lens in the same way as is accomplished for visual light. A disadvantage of the microscope is that a long exposition is required due

\footnotetext{
*Correspondence: e-mail: dudchik@bsu.by
}

Advances in X-Ray/EUV Optics and Components II, edited by Ali M. Khounsary, Christian Morawe, Shunji Goto, Proc. of SPIE Vol. 6705, 670509, (2007) · 0277-786X/07/\$18 - doi: 10.1117/12.731731 
to the fact that the intensity is small at the image plane.

Here we new present projection- type X-ray microscope with a compound refractive lens as an optical element. The microscope looks like one described in [9], the only difference is that the X-ray source, lens and X-ray camera are placed at distances to satisfy lens formula. Object for imaging is placed closely to X-ray source and an image is formed, as in the case of imaging with microspot tube, by absorbed (transmitted) X-rays.

\section{LENS PARAMETERS}

The scheme of projection- type X-ray microscope is shown in Fig.1. The microscope consists of an X-ray source -1, compound refractive X-ray lens -2 and X-ray camera - 3 , that are placed in-line to satisfy the lens formula

$$
\frac{1}{s_{1}}+\frac{1}{s_{2}}=\frac{1}{f},
$$

where $s_{1}=a_{1}+a$ is distance from the source to the lens, $s_{2}=b$ is distance from the lens to the CCD-camera, $f$ - lens focal length. The lens is used to form an image of the X-ray source at camera sensitive plate. An object for investigation 4 is placed between the X-ray source and the lens as close as possible to the source, and the camera shows a shadow image of the object. Spatial resolution of the microscope $d$ in the plane perpendicular to the optical axis depends on the lens focal length $f$, lens aperture $2 r_{s}$ and the distance from the source to the object, and may be calculated as:

$$
d=\frac{2 r_{s}}{\left(a_{1}+a\right)} a_{1}
$$

where $a_{1}$ - is distance from the X-ray source to the object, $a$ - is distance from the object to the lens as it is shown in Fig.1. One to two micron resolution may be achieved by placing the object at a distance of $1-5 \mathrm{~mm}$ from the source. It is really possible because the X-ray source may be designed as X-ray tube with the target deposited on a $200-\mu \mathrm{m}$ thick Be window, which permits the object to be placed very close to the emitting surface.

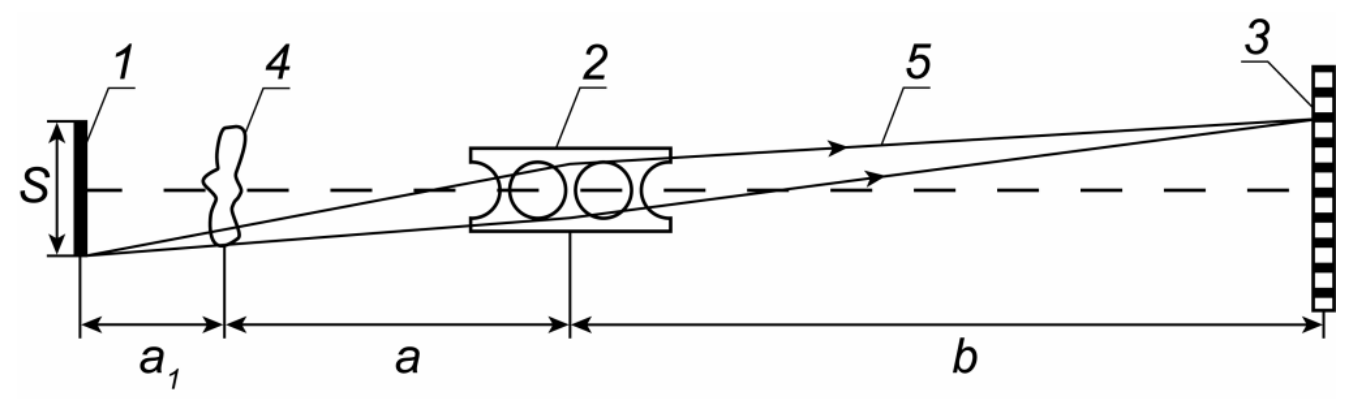

Fig.1. Scheme of projection- type X-ray microscope. 1- X-ray source, 2- compound refractive X-ray lens, 3- X-ray camera , 4- object.

Refractive X-ray lens used for the microscope was designed in the form of glass capillary filled by 137 spherical, biconcave, epoxy microlenses. The lens was produced in Institute of Applied Physics Problems of Belarus State University by the method described in [10-12]. Fig.2 shows photo of epoxy concave microlenses inside glass capillary. The microlenses were formed inside capillary with inner diameter equals to 200 microns. The curvature radius $\mathrm{R}$ of each microlens is equals to curvature radius of capillary and thus equals to 100 microns. Lens focal length $f$ of compound refractive lens is calculated as: 


$$
f=\frac{R}{2 N \delta}
$$

where $R$ - curvature radius, $N$ - number of microlenses, $(1-\delta)$ - real part of refractive index for X-rays. Parameter $\delta$ for used epoxy may be calculated from the epoxy chemical formula as

$$
\delta=0.5\left(\frac{22}{E}\right)^{2}
$$

where $E$ is photon energy measured in $\mathrm{eV}$. Experiments on measuring lens focal length of compound epoxy lenses at Stanford Synchrotron Radiation Laboratory and Advanced Photon Source shown validity of formula 4 for calculation lens focal length $[13,14]$.

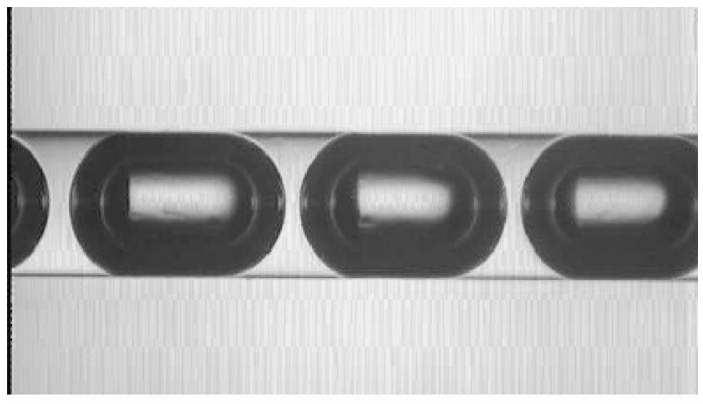

Fig.2. Photo of epoxy concave microlenses inside glass capillary with diameter 200 microns.

Compound X-ray lenses consisting of spherical microlenses may be characterized by absorption aperture radius $R_{a}$ that in a good approximation can be calculated as:

$$
R_{a}=\left(\frac{2 R}{\mu N}\right)^{\frac{1}{2}},
$$

where $\mu$ is the linear absorption coefficient for the lens material.

The discussed X-ray lens is a linear combination of spherical microlenses and spherical aberrations occur just in the same way as for spherical visual-light lens. To take into account this phenomenon at least two planes around the lens focus may be denoted: they are shown by the lines MS and PP in Fig.3 which shows trajectories of 8-keV X-rays forming focal spot of compound lens consisting of 103-microlenses.

The plane PP represents a focal plane. The plane MS represent the circle of the least confusion [15]. For spherical lens the size of X-ray beam at MS and PP planes may be decreased by using diaphragm. The beam radius $R_{p p}$ at the PPplane depends on the radius of used diaphragm $R_{d}$ and is calculated from the third order aberration theory as [15 ]:

$$
R_{p p}=f B R_{d}{ }^{3}
$$

where $f$ is the lens focal length, $B$ is Seidel coefficient, $R_{d}$ is radius of the diaphragm placed before the lens. Eq. 6 is valid for the case of the point source located at the infinity. As it was shown in [11], the equation (6) for compound X-ray lens is rewritten as 


$$
R_{p p}=\frac{1}{2} \frac{R_{d}^{3}}{R^{2}} .
$$

The eq. 7 is valid for the case when $R_{d}<0.6 R$ as was estimated in [11] by numerical calculations. The beam radius $R_{m s}$ at the MS-plane is related to the beam radius $R_{p p}$ at the focal plane as

$$
R_{m s}=\frac{1}{4} R_{p p}=\frac{1}{8} \frac{R_{d}^{3}}{R^{2}} .
$$

The distance $L_{m s}$ from the lens to MS-plane is calculated as:

$$
L_{m s}=f \frac{\left(R_{d}+R_{m s}\right)}{\left(R_{d}+R_{p p}\right)} .
$$

For example $L_{m s}=0.917 \mathrm{f}$ when $R_{d}=0.5 \mathrm{R}$ and it is illustrated by Fig. 3 where position of MS- plane is shown for the discussed case.

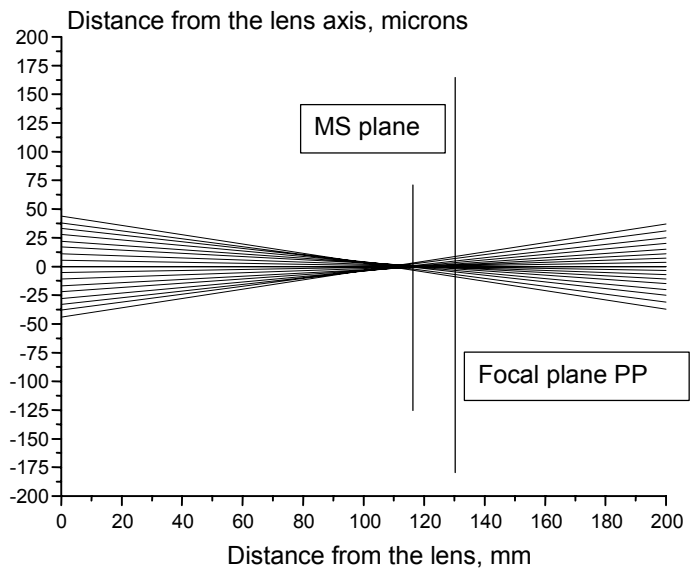

Fig. 3. Paths of $8-\mathrm{keV}$ X-rays forming focal spot of 103elements lens. Lens radius is 100 microns. Diameter of the diaphragm placed before the lens is equals to 100 microns.

Radius $R_{m s}$ of the circle of the least confusion decreases with decreasing of the size of diaphragm and achieves its minimum possible value $R_{m s-m i n}$ when a diaphragm with an optimal hole radius $R_{d-o p t}$ is used. In this case the value $R_{m s-}$ min will be equals to the radius of the first minimum of the Airy diffraction pattern $R_{\text {diff }}$ which is $R_{\text {diff }}=0.61 \lambda L_{m s} / R_{d-o p t}$. The diaphragm radius $R_{d-o p t}$ may be defined by the following equation:

$$
\frac{1}{8} \frac{R_{d-o p t}^{3}}{R^{2}}=\frac{0.61 \lambda L_{m s}}{R_{d-o p t}}
$$

where $\lambda$ is the wavelength. The solution of the Eq. (10) for $R_{d-o p t}$ and for $R_{m s-\min }$ under the assumption $L_{m s}=f$ are:

$$
R_{d-o p t}=\left(\frac{2.44 R^{3} \lambda}{\delta N}\right)^{1 / 4}
$$


and

$$
R_{m s-\min }=\frac{0.61 \lambda f}{R_{d-o p t}} .
$$

It is interesting to compare above result for $R_{d-o p t}$ (Eq. 11) with the value of so-named parabolic aperture radius $R_{p}$. Parabolic aperture radius $R_{p}$ is the central portion of the spherical lens that focuses X-rays to the same point. From wave approximation it is known $[1,3,16]$ that the value may be calculated as:

$$
R_{p}=\left(\frac{2 R^{3} \lambda}{\delta N}\right)^{1 / 4}
$$

Comparing Eq.11 and Eq.13 we can see that there is only a small deference in numerical coefficient for these two values. It may be explained that we used $f$ value instead of $L_{m s}$ when solving Eq. 10 .

Eq. (11) for $R_{d-o p t}$ and Eq. (12) for $R_{m s-\min }$ are useful to calculated expected X-ray beam size in the MS plane for compound X-ray lenses. In Table 1 and Table 2 diameter $2 R_{m s}$ of the circle of the least confusion is calculated for epoxy spherical lenses with deferent values of number of microlenses $N$ and lens radius $R$. Table 2 shows result of the same calculations for the case when additional diaphragm is used to decrease size of the beam at MS plane.

From the Table 2 it is seen that spherical compound refractive lens being combined with diaphragm ensures resolution at submicron level.

Table 1. Parameters of X-ray beam formed by spherical compound epoxy X-ray lens.

\begin{tabular}{|c|c|c|c|c|}
\hline Lens parameters & $\begin{array}{c}\text { Lens focal length } \mathrm{f} \text { for } \\
8 \mathrm{keV} \text { X-rays, } \mathrm{mm}\end{array}$ & $\begin{array}{c}\text { Lens absorption aperture } \\
\text { 2Ra, } \mu \mathrm{m}\end{array}$ & $\begin{array}{c}\text { Lms value for } 8 \mathrm{keV} \\
\text { X-ray beam, } \mathrm{mm}\end{array}$ & $\begin{array}{c}\text { Diameter } 2 \mathrm{R}_{\mathrm{ms}} \\
\text { of the circle of } \\
\text { the least } \\
\text { confusion, } \mu \mathrm{m}\end{array}$ \\
\hline $\mathrm{N}=100, \mathrm{R}=100 \mu \mathrm{m}$ & 132 & 117 & 117.5 & 5 \\
\hline $\mathrm{N}=200, \mathrm{R}=100 \mu \mathrm{m}$ & 66 & 82 & 62 & 1.72 \\
\hline $\mathrm{N}=100, \mathrm{R}=50 \mu \mathrm{m}$ & 66 & 82 & 53.5 & 6.89 \\
\hline $\mathrm{N}=200, \mathrm{R}=50 \mu \mathrm{m}$ & 33 & 58 & 29.4 & 2.44 \\
\hline
\end{tabular}

Table 2. Parameters of X-ray beam formed by spherical compound X-ray lens combined with diaphragm.

\begin{tabular}{|c|c|c|c|c|}
\hline Lens parameters & $\begin{array}{c}\text { Lens focal length } \mathrm{f} \text { for } \\
8 \mathrm{keV} \text { X-rays, } \mathrm{mm}\end{array}$ & $\begin{array}{c}\text { Diameter of the optimal } \\
\text { diaphragm aperture } \\
\text { 2Ropt, } \mu \mathrm{m}\end{array}$ & $\begin{array}{c}\text { Lms value for } 8 \mathrm{keV} \\
\text { X-ray beam, } \mathrm{mm}\end{array}$ & $\begin{array}{c}\text { Diameter 2 } \\
\text { of the circle of } \\
\text { the least } \\
\text { confusion, } \mu \mathrm{m}\end{array}$ \\
\hline $\mathrm{N}=100, \mathrm{R}=100 \mu \mathrm{m}$ & 132 & 62 & 127.4 & 0.78 \\
\hline $\mathrm{N}=200, \mathrm{R}=100 \mu \mathrm{m}$ & 66 & 53.2 & 64.3 & 0.46 \\
\hline $\mathrm{N}=100, \mathrm{R}=50 \mu \mathrm{m}$ & 66 & 37.6 & 62.7 & 0.66 \\
\hline $\mathrm{N}=200, \mathrm{R}=50 \mu \mathrm{m}$ & 33 & 31.6 & 31.8 & 0.39 \\
\hline
\end{tabular}

\section{X-RAY MICROSCOPE}


We used a copper-anode X-ray tube (Russian model \# BCV-17) with tube focal spot of $0.6 \mathrm{~mm} \times 8 \mathrm{~mm}$ as a source of 8-keV X-rays for the microscope. The angle between X-ray tube anode mirror and the X-ray beam was 6 degrees and thus the effective tube focal spot was equal to $0.6 \mathrm{~mm} \mathrm{X} 0.8 \mathrm{~mm}$. The X-ray tube was cooled by water; tube voltage was $32 \mathrm{kV}$ and current- $14 \mathrm{~mA}$. The object for imaging 4 (see Fig.1) was placed very closely to tube beryllium window. The distance between X-ray tube anode spot and beryllium window was equal approximately to $20 \mathrm{~mm}$.

The lens used as objective for the microscope consists of 137 individual spherical, biconcave, microlenses, each with 100-microns curvature radius $R$. Lens length is equal to $55 \mathrm{~mm}$. The lens focal length, calculated in accordance to the Eq. 3 , is $96.5 \mathrm{~mm}$ for $8 \mathrm{keV} \mathrm{X-rays.} \mathrm{This} \mathrm{result} \mathrm{should} \mathrm{be} \mathrm{corrected} \mathrm{for} \mathrm{effect} \mathrm{of} \mathrm{lens} \mathrm{thickness.} \mathrm{As} \mathrm{it} \mathrm{was} \mathrm{shown} \mathrm{in} \mathrm{[17],} \mathrm{the}$ focal length $f_{t}$ of a "thick" lens is calculated as :

$$
f_{t}=f \frac{\left(\frac{t}{f}\right)^{1 / 2}}{\sin \left(\frac{t}{f}\right)^{1 / 2}},
$$

where $t$ is lens length. Result is $f_{\mathrm{t}}=106.3 \mathrm{~mm}$ for the discussed 137 -unit lens and $8-\mathrm{keV} \mathrm{X-rays.} \mathrm{For} \mathrm{a} \mathrm{"thick"} \mathrm{lens} \mathrm{the}$ lens formula (1) may be rewritten as [17]:

$$
\frac{1}{r_{0}}+\frac{1}{r_{l}}=\frac{1}{f_{t}},
$$

where $r_{0}$ - distance from the source to a back principle plane of a "thick" lens, $r_{l}$ - distance from a forward principle plane of a "thick" lens to image plane (plane of the X-ray camera). The distance $d$ between forward and back principle planes of the lens is calculated as [17]:

$$
d=f_{t}\left[1-\cos \left(\frac{t}{f_{t}}\right)^{1 / 2}\right] .
$$

The image of the object was recorded by a Marshal B/W CMOS camera with 510 x 492 pixels, format 1/3", without a glass cover. Data for position of the X-ray tube, lens and CMOS-camera were found with Eqs. 14-15: the distance from the anode target to the center of 137 -unit lens was equal to $131 \mathrm{~mm}$, the camera was placed at the distance $392 \mathrm{~mm}$ to the lens center. The camera recorded 2.8 times increased image of X-ray tube spot.

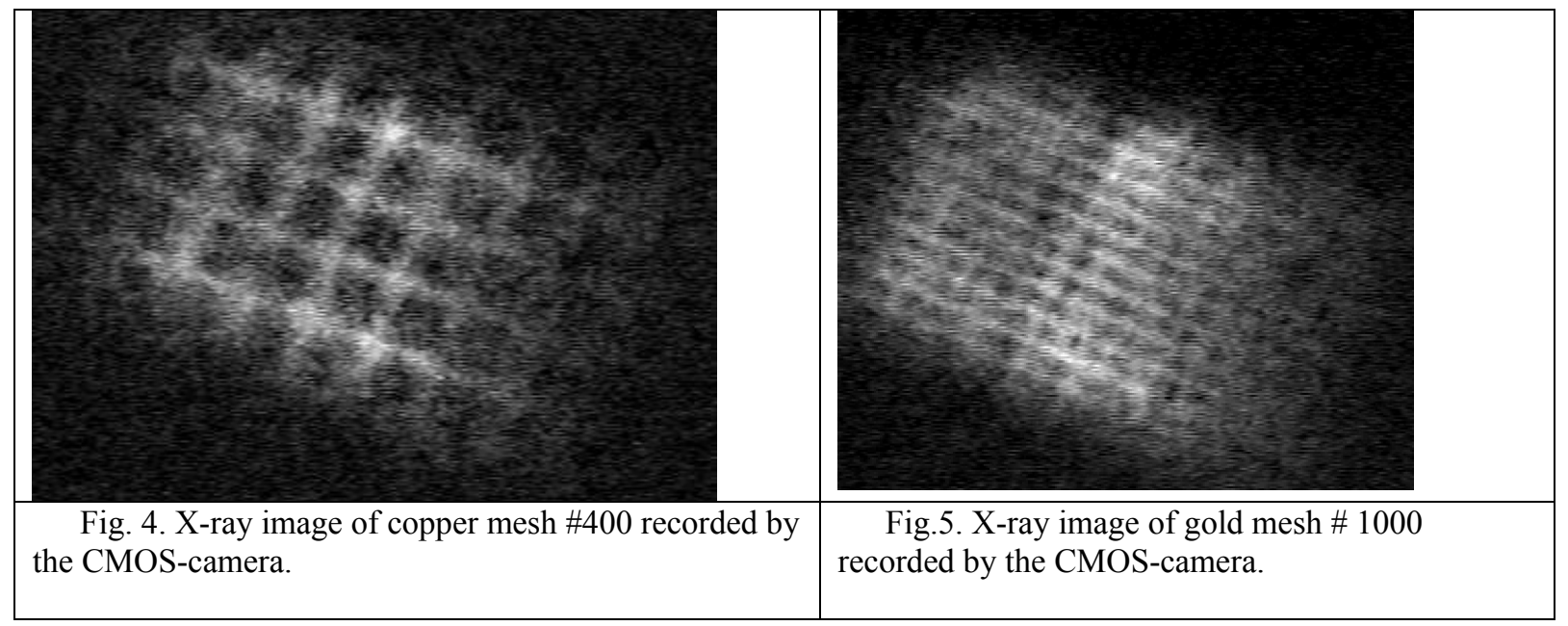


Two metal meshes were used as objects for imaging: copper mesh \#400, and gold mesh \#1000. The mesh \#1000 consists of 5 microns thick wires, with a wire center to center separation of 18 microns. Figs. 4, 5 are images of metal meshes recorded by the CMOS-camera.

As it can be seen from Fig.5, 5-microns gold wires are really recognized by the camera and we may conclude that the spatial resolution of the discussed projection X-ray microscope is not worse than 5 microns. Better resolution can't be achieved at a given experimental conditions because the pixel size of the used CMOS-camera is equals to $10 \mu \mathrm{m} \mathrm{X}$ $13.5 \mu \mathrm{m}$ and the magnification is only 2.8. Another reason may be that, as was shown in Table 1, the size of circle of the least confusion for the used lens is about 5 microns.

The field of view of discussed microscope depends on lens focal length, lens lengths and is defined by beams which pass from extreme points of the source through the center of the lens. For a considered case the field of view is about 1 $\mathrm{mm}$.

\section{DISCUSSION}

Experimental investigation shown that the resolution power of the discussed projection X-ray microscope with spherical compound X-ray lens is not worse than 5 microns. Submicron resolution may be achieved by using diaphragm with diameter approximately equal to $0.3 D$ to decrease lens spherical aberrations, where $D$ is lens diameter.

\section{ACKNOWLEDGMENTS}

This work was partly supported by the Byelorussian Foundation of Fundamental Investigations (Grant \# F06MC011).

\section{REFERENCES}

1. A. Snigirev, V. Kohn, I. Snigireva and B. Lengeler, "A Compound Refractive Lens for Focusing High-Energy Xrays", Nature (London) 384, 49 (1996).

2. Toshihisa Tomie, US Patent No. 5,594,773 (14 Jan. 1997) Foreign Appl. Date Feb. 18, 1994, Japan No. 6-45288.

3. M. A. Piestrup, R. H. Pantell, J. T. Cremer and H. R. Beguiristain, "Compound Refractive Lens for X-rays," US Patent, 6,269,145 B1, allowed Jul. 31, 2001.

4. W. Yun, B. Lai, Z. Cai, J. Maser, D. Legnini, E. Gluskin, Z. Chen, A. A. Krasnoperova, Y. Vladimirsky, and F. Cerrina, E. Di Fabrizio and M. Gentili, "Nanometer focusing of hard x rays by phase zone plates", Rev. Sci. Instr. 70(5) 2238(1999).

5. G.-C. Yin, Y.-F. Song, M.-T. Tang, F.-R. Chen, K. S. Liang, F. W. Duewer, M. Feser, W. Yun, H.-P. D. Shieh. "30 $\mathrm{nm}$ resolution $\mathrm{x}$-ray imaging at $8 \mathrm{keV}$ using third order diffraction of a zone plate lens objective in a transmission microscope" Appl. Phys. Lett. 89, 221122 (2006).

6. B. Lengeler, C. G. Schroer, M. Richwin, J. Tümmeler, M. Drakopolulos, A. Snigirev, and I. Snigireva, "A Microscope for Hard X rays Based on Parabolic Compound Refractive Lenses", Appl. Phys. Lett. 74, 3924 (1999).

7. C. G. Schroer, J. Meyer, M. Kuhlmann, B. Benner, T. F. Günzler, B. Lengeler, C. Rau, T. Weitkamp, A. Snigirev, I. Snigireva, "Nanotomography based on hard x-ray microscopy with refractive lenses", Applied Physics Letters 81 (8), $1527(2002)$.

8. S. C. Mayo, T. J. Davis, T. E. Gureyev, P. R. Miller, D. Paganin, A. Pogany, A. W. Stevenson, and S. W. Wilkins, "X-ray phase-contrast microscopy and microtomography," Opt. Express 11, 2289(2003).

9. M.A.Piestrup, C.K.Gary, H.Park, J.L.Harris, J.T.Cremer, R.H.Pantell, Yu.I.Dudchik, N.N.Kolchevsky, F.F.Komarov, "Microscope using an X-ray tube and a bubble compound refractive lens", Appl. Phys. Letters, 86, 131104-1(2005).

10. Yu.I.Dudchik, N.N.Kolchevsky, "A microcapillary lens for X-rays", Nucl. Instr.Meth. A 421, 361 (1999).

11. Yu.I.Dudchik, N.N.Kolchevsky, F.F.Komarov,Y.Kohmura, M.Awaji, Y.Suzuki, T.Ishikawa, "Glass capillary X-ray lens: fabrication technique and ray tracing calculations" Nucl.Instr.Meth. A 454, 512 (2000). 
12. Yu. I. Dudchik, N.N. Kolchevsky, "Fabrication technique and ray tracing calculations for microcapillary x-ray lens", SPIE Proceedings. Advances in X-Ray Optics, 4145 , 235 (2001).

13. Yu.I.Dudchik, N.N.Kolchevsky, F.F.Komarov, M.A.Piestrup, J.T.Cremer, C.K.Gary, R.H.Pantell, "Short-focallength compound refractive lenses for X-rays," Proceedings of SPIE 5194, 56 (2004).

14. Yu.I.Dudchik, N.N.Kolchevsky, F.F.Komarov, M.A.Piestrup, J.T.Cremer, C.K.Gary H.Park and A.M.Khounsary, "Microspot X-ray focusing using short-focal length compound lenses," Rev. Sci. Instr. 75(11), pp.4651-4655 (2004).

15. M.Born and E.Wolf, Principles of Optics, 5th ed., Pergamon Press, Elmsford, N.Y.,1975.

16. M. A. Piestrup, H. R. Beguiristain, C. K. Gary, J. T. Cremer, R. H. Pantell and R. Tatchyn, "Compound Refractive Lenses for Novel X-ray Sources" Nuclear Instruments and Methods B 173, 170 (2001).

17. R. H. Pantell, J. Feinstein, H. R. Beguiristain, M. A. Piestrup, C. K. Gary and J. T. Cremer, "Characteristic of the thick compound refractive lens" Applied Optics 42, 719(2003). 